Running head: CAREGIVER DEPRESSION AND PARENTING

\title{
The Relationship among Caregiver Depressive Symptoms, Parenting Behavior, and Family-center Care
}

Deborah Winders Davis, PhD, , John Myers, PhD, M. Cynthia Logsdon, PhD, C-WHNP, FAAN, Nerissa S. Bauer, MD, MPH

All authors have no financial interests or potential conflicts of interest to disclose.

Key Words: early childhood, parent mental health

This is the author's manuscript of the article published in final edited form as:

Davis, D. W., Myers, J., Logsdon, M. C., \& Bauer, N. S. (2016). The Relationship Among Caregiver Depressive Symptoms, Parenting Behavior, and Family-Centered Care. Journal of Pediatric Health Care, 30(2), 121-132. http://doi.org/10.1016/j.pedhc.2015.06.004 


\begin{abstract}
Background and Objective: Parental depression has been associated with adverse child outcomes. However, the specific parenting behaviors that may result in such child outcomes and what effect family-centered care (FCC) has on positive parenting behavior of depressed parents has not previously been examined.

Methods: Data from the National Survey of Early Childhood Health (NSECH) was used ( $n=$ 2,068). Groups were stratified by the presence of parental depression and compared on demographics and mean number of specific positive parenting behaviors. Generalized linear models were developed based on testing whether individuals performed more or less than the median number positive behaviors. Lastly, we tested whether depression independently predicted each outcome after adjustment for FCC, coping, social support and ethnicity to evaluate if depression independently predicted each outcome after adjustment.
\end{abstract}

Results: There was no difference in demographic variables between those who were depressed and not depressed. Those not depressed performed significantly more routines $(p=0.036)$; reported coping better with parenting $(p<0.001)$; performed significantly less punitive behaviors $(p=0.022)$ and needed/had less social support $(p=0.002)$ compared to those depressed. Individual items and scale scores were associated in the expected directions. FCC was independently associated with study variables, but did not moderate the effect of depression. Conclusions: These data identify specific parenting behaviors that differ between parents who report depressive symptoms compared to those without depressive symptoms. More targeted interventions coordinated through a medical home are needed for parents with depressive symptoms to reduce the child health disparities often associated with parental depression. 
The Relationship among Caregiver Depressive Symptoms, Parenting Behavior, and Familycenter Care

Major depressive disorders occur in approximately $20 \%$ of adult females (Yonkers, Vigod, \& Ross, 2011). Women of childbearing age have been reported to be of particular risk, especially during the first postpartum year (Viguera et al., 2011; Yonkers et al., 2011). The prevalence of less severe forms of depression is less well known, but one study reported the presence of depressive symptoms in almost $40 \%$ of a sample of inner-city mothers (Heneghan, Silver, Bauman, Westbrook, \& Stein, 1998). It has been well-established that maternal depression is associated with numerous adverse child health and developmental outcomes (Cornish et al., 2005; Gartstein \& Fagot, 2003; Kurstjens \& Wolke, 2001; Logsdon, Wisner, \& Pinto-Foltz, 2006; NICHD Early Child Care Research Network, 1999; Petterson \& Albers, 2001; Teti, O'Connell, \& Reiner, 1996; Tronick \& Reck, 2009). In general, the mechanisms through which depression influences child outcomes are related to the interference of optimal parentchild interactions and with maternal-role functioning (Berkule et al., 2014; Logsdon et al., 2006; NICHD Early Child Care Research Network, 1999). Most of the research, to date, focuses on maternal depression, but the mental health of fathers has also been reported to be a risk factor for adverse child outcomes (Fletcher, Feeman, Garfield, \& Vimpani, 2011; Ramchandani et al., 2011; Ramchandani, Stein, Evans, O'Connor, \& Alspac study team, 2005).

More data are needed to identify specific parenting behaviors that may be influenced by parental depression in order to target preventive interventions that support positive parenting in the face of parental depression. For example, it has been shown that mothers suffering from depression have interaction styles characterized as withdrawn or intrusive (Field, 1998). Each of these interaction styles has consequences for how parents with depression manage day-to-day 
parenting tasks necessary for child health, safety, and development (Berkule et al., 2014). The relationships are complex and parental depression interacts with other factors such as socioeconomic status, race and ethnicity, maternal sensitivity, and social support (Campbell, Matestic, von Stauffenberg, Mohan, \& Kirchner, 2007; Clare \& Yeh, 2012; Logsdon, Mcbride, \& Birkimer, 1994; Wang, Wu, Anderson, \& Florence, 2011).

It is clear from the literature that parental depression, especially maternal depression, is a serious problem and depression affects parental functioning and child outcomes. Some national organizations recommend screening and initial management of postpartum depression in primary care settings (Earls \& The Committee on Psychosocial Aspects of Child and Family Health, 2010; National Institute for Health Care Management, 2010), while others have suggested that there is not yet enough evidence to recommend universal screening, but suggest that it should be considered (American College of Obstetricians and Gynecologists, 2010). Because of the detrimental effects parental depression has on childhood development and other health-related outcomes (Kurstjens \& Wolke, 2001; Maughan, Cicchetti, Toth, \& Rogosch, 2007; Ramchandani et al., 2005; Santos, Matijasevich, Domingues, Barros, \& Barros, 2010), pediatricians and pediatric nurse practitioners are often assuming a primary role in identifying and referring caregivers for suspected depression. However, few interventions aimed specifically at depressed mothers exist for delivery within pediatric primary care settings (Bauer, Stanton, Carroll, \& Downs, 2013; Berkule et al., 2014). Family-centered care (FCC) is an approach to planning and coordinating care that ensures comprehensive health management for children and families that is individualized to meet the needs of each family (Committee on Hospital Care Institute for Patient- and Family-Centered Care, 2012; National Association of Pediatric Nurse Practitioners' Health Policy Committee, 2015). High quality FCC has been shown to improve 
health-related resource utilization and reduce costs (J. E. Cox, Buman, Woods, Famakinwa, \& Harris, 2012; DeVries et al., 2012; Long, Bauchner, Sege, Cabral, \& Garg, 2012; Romaire, Bell, \& Grossman, 2012). Although not specific to depression, family-based approaches within primary care have potential for effectively intervening with families affected by parental depression (Beardslee, Gladstone, Wright, \& Cooper, 2003). More data are needed to better understand the role of specific models of care, such as FCC, in the provision of optimal care and targeted anticipatory guidance for families in which one or more parent suffers from depression. However, previous examinations of data contained within the National Survey of Early Childhood Health (NSECH) 2000 dataset did not adjust for this important potential confounder when examining the relationship between parental depression and parenting behaviors (Blumberg \& O'Connor, 2004; Kogan et al., 2004; Mistry, Stevens, Sareen, De Vogli, \& Halfon, 2007; Regalado, Sareen, Inkelas, Wissow, \& Halfon, 2004).

The current study evaluated whether parental depression independently predicted specific parenting behaviors (routines, enrichment, punitive disciplinary behaviors, positive disciplinary strategies, and home safety [childproofing]) after adjusting for FCC and traditional risk factors (coping, social support, and ethnicity). Our hypothesis is that the association of suboptimal parenting among caregivers who experience depressive symptoms would be lessened if the family received FCC delivered in the context of a primary care home.

\section{Sample}

\section{Methods}

The National Survey of Early Childhood Health (NSECH) is a telephone survey of a national random sample of 2,068 parents of children between ages 4 and 35 months conducted by the National Center for Health Statistics (NCHS) in 2000 (Blumberg, Olson, \& Osborn, 2002). African-American and Latino children were oversampled to provide a nationally 
representative sample of underrepresented populations suitable for subgroup analyses. Most respondents were mothers $(94 \%)$ of the sampled child; the remaining were fathers $(5 \%)$ or grandparents (1\%). The response rate was $65.6 \%$. A more complete description of the NSECH is presented elsewhere (Blumberg et al., 2002).

\section{Procedure}

Structured telephone interviews of approximately 30 minutes were conducted in English or Spanish with parents, and questions addressed the content and quality of early childhood health care. The aim of the original NSECH was to assess parents' perceptions of the primary health care their child was receiving (Blumberg et al., 2002).

\section{Variables}

All questions were on a Likert-type scale with variable response options as will be described for each variable. All questions had a response option of "Don't know" and "Refused." Each variable is described in more detail below. In general, we deleted the "Don't know" and "Refused" responses; reverse-coded items, where appropriate; summed the scores; and either used the score as a continuous variable or created a dichotomous variable using a median split.

Depression. Depression was measured using the five-item Mental Health Inventory (MHI-5) (McHorney, Ware, Rogers, Raczek, \& Lu, 1992), which is a validated and brief measure derived from the original Short form Health Survey Questionnaire (SF-36) (McHorney \& Ware, 1995). The MHI-5 uses a six-point response scale from "All of the time" to "None of the time" (McHorney et al., 1992). Both versions have been validated for use with diverse populations and have adequate psychometric properties (Berwick et al., 1991; Kelly, Dunstan, Lloyd, \& Fone, 2008; Leiferman, Ollendick, Kunkel, \& Christie, 2005; McHorney \& Ware, 1995; McHorney, Ware, Lu, \& Sherbourne, 1994; McHorney, Ware, \& Raczek, 1993; 
McHorney et al., 1992). Each of the questions refers to how the participant felt during the past month. How much of the time have you 1) been a very nervous person? 2) felt calm and peaceful? 3) felt downhearted and blue? 4) felt so down in the dumps that nothing could cheer you up? and 5) been a happy person? Lastly, we summed the responses for the five questions and, then, transformed the raw scores (range 0-100) as has been typically done in the literature. No consensus has been reached on what cut-off score should be used to indicate depression (Kavanaugh et al., 2006; Kelly et al., 2008; Mistry et al., 2007). Most recently, Kelly and colleagues used five statistical methods that yielded scores of 60, 68, and 76 (Kelly et al., 2008). We selected 68 to define depressed vs. not depressed (Cronbach's alpha $=0.810$ ).

Parenting behaviors. Parenting behaviors included routines, enrichment, punitive disciplinary behaviors, positive disciplinary strategies, and childproofing (see descriptions below). Recent literature has defined positive parenting behaviors that have been associated with optimal child health and developmental outcomes as well as negative parenting behaviors that have been associated with adverse child outcomes (Belsky \& Jaffee, 2006; Belsky \& Pluess, 2009; Chronis et al., 2007; de Graaf, Speetjens, Smit, de Wolff, \& Tavecchio, 2008a, 2008b; Juffers, Bakersmans-Kraneburg, \& Van Ijzendoorn, 2008a, 2008b; Landry \& Smith, 2011; Landry, Smith, \& Swank, 2006; Landry, Smith, Swank, \& Guttentag, 2008; Matsumoto, Sofronoff, \& Sanders, 2010; Morrongiello \& Kiriakou, 2004; Mulvaney \& Mebert, 2010; Nowak \& Heinrichs, 2008; Perrin, Sheldrick, McMenamy, Henson, \& Carter, 2014; Sanders, Bor, \& Morawska, 2007; Shonkoff, 2010; Shonkoff, Garner, et al., 2012; Spijkers, Jansen, de Meer, \& Reijneveld, 2010; Tamis-LeMonda \& Baumwell, 2011; Thomas \& Zimmer-Gembeck, 2007; Vanderveen, Bassler, Robertson, \& Kirpalani, 2009; Wiggins, Sofronoff, \& Sanders, 2009). The 
parenting behaviors described below fit with the current conceptualization of positive and negative parenting behavior.

Routines. Routines were defined by five questions. The first three were scored as "Same every day" or "Changes from day to day." Those three questions are as follows. Is (CHILD'S) bedtime usually the same time each day? Is (CHILD'S) nap time usually the same every day? Are (CHILD'S) mealtimes usually the same every day? Two additional questions were scored on a 4-point scale from "Every day" to "Never." These two questions are as follows. How many days in a typical week does everyone in the household eat a mid-day or evening meal together? How many days in a typical week does everyone in the household eat breakfast together?

Environmental structure, including routines, has been associated with the development of self-regulatory functioning, more positive developmental outcomes, and school readiness (Bradley, 2002; Dilworth-Bart, Khurshid, \& Vandell, 2007; Matheny, Wachs, Ludwig, \& Phillips, 1995; Visser et al., 2014; Wachs, 1993). Depression is a known risk factor for adverse child outcomes (Chronis et al., 2007), but it is not known if depression might interfere with a mother's ability to provide daily routines.

Enrichment. Enrichment was defined by three questions with a 4-point response option from "Every day" to "Never" as follows: Please tell me the number of days in a typical week that you or any other family members do the following activities, 1) read stories to (CHILD), 2) play music or sing songs with (CHILD), and 3) take (CHILD) on any kind of outing such as the park, grocery, church, or a playground.

Punitive disciplinary behaviors. Punitive disciplinary behaviors were defined by two questions with a 4-point response option from "Often" to "Never." Parents were asked to say 
how often they used raising their voices or yelling and spanking as methods of disciplining their child.

Positive disciplinary strategies. Positive disciplinary strategies were defined by three questions with a 4-point response scale from "Often" to "Never" when asked about the frequency of each disciplinary practice. How often do you 1) take away a toy or treat? 2) give a time-out (that is making (CHILD) take a break) from what activity [he/she] is doing? and 3) explain to (CHILD) why [his/her] behavior is not appropriate?

Childproofing. Childproofing was defined by six questions that had the response options of "Yes," "No," or "Not applicable." Parents were told they were going to be read a list of things that parents sometimes do to childproof their home or to make it safe and they were to say if they ever did that in their home. The items were as follows: 1) put up baby gates, window guards, or other barriers; 2) put locks or safety latches on cabinets where such things as cleaning supplies or medicines are kept; 3 ) padding hard surfaces or sharp edges; 4) put stoppers or plugs in outlets; 5) turn down hot water thermostat setting; and 6) Syrup of Ipecac can be used if (CHILD) swallows something poisonous. Do you have Syrup of Ipecac at home?

Covariates. Covariates included coping, social support, FCC, and race/ethnicity. Coping. Coping was defined by one question with a 4-point response scale from "Very well" to "Not well at all" as follows: How well do you feel you are coping with the day to day demands of parenthood?

Social support. Social support was defined by two questions with a 4-point response scale (Cronbach's alpha $=0.848)$ from "Very well" to "Not well at all" as follows: 1) Is there someone you can turn to for day to day emotional help while parenting? 2) Do you have someone you can count on to watch the (CHILD) if you need a break? 
Family-centered care (FCC). FCC was defined by 4 questions with a 4-point response scale (Cronbach's alpha $=0.820)$ from "Always" to "Never." Each of the questions refers to the past year. How often did (CHILD'S) doctor or health provider 1) take time to understand specific needs of (CHILD'S)? 2) respect your expertise? 3) ask how you are feeling as a parent? and 4) understand you and your family and how you prefer to raise (CHILD)?

These questions fit with the core principles of patient- and family-centered care that have been described in a policy statement from the American Academy of Pediatrics (Committee on Hospital Care and Institute for Patient- and Family-Centered Care, 2012). In brief, the statement suggests that a collaborative relationship be established among the patients, families, doctors, nurses, and other health care professionals for the planning, delivery, and evaluation of health care. Additionally, the relationship should be guided by the following principles, which are summarized from the policy statement: 1) listening to and respecting individual needs of each child and his/her family; 2) providing services that are tailored to the needs, beliefs, and cultural values of each child and family; 3) sharing unbiased information that is useful to the family so that they can effectively participate in care and decision-making; 4) providing and/or ensuring formal and informal support throughout the child's life; and 5) collaborating with patients and families in all areas of care delivery, research, program development, etc. (Committee on Hospital Care and Institute for Patient- and Family-Centered Care, 2012).

Race/ethnicity. Respondents were allowed to identify all possible categories that described race. If a race other than the seven existing categories was indicated, then verbatim responses were recorded. Verbatim responses were reviewed and matched against a database of alternate nomenclature maintained by the U.S. Census Bureau and back-coded into one of the seven categories. White (Non-Hispanic White), Hispanic and Black or African American was 
coded as such for the current analysis and represented $97.5 \%$ of respondents. Native American, Alaska Native, Asian, Native Hawaiian, Pacific Islander and Other were coded as "Other" for analysis, to achieve statistical inference (Cronbach's alpha $=0.664)$.

\section{Statistical Analysis}

To test the effect of receipt of FCC on the association of suboptimal parenting among caregivers with depressive symptoms, we first conducted a preliminary analysis and calculated correlation coefficients (Pearson or Spearman, when appropriate) for all predictor variables to test if depression co-varied with any other predictor. Additionally, we performed a descriptive analysis of demographics stratified by those who had depressive symptoms and those who did not have depressive symptoms. Chi-square analysis was used to test for differences between those depressed and those not depressed for categorical variables, while independent-samples ttests were used to test for differences in continuous variables. Similarly, independent-samples ttests were used to test for differences in the mean number of positive parenting behaviors, while Wilcoxon methods were used to test for differences in median number of positive parenting behaviors stratified by presence of depressive symptoms. Chi-square analysis was used to test whether those who were not depressed were more/less likely to adhere to advocated individual positive parenting behaviors (unadjusted).

Lastly, we tested whether individuals performed more/less than the median number positive behaviors by developing generalized linear models (using the binomial distribution and logit link function). That is, for example, if an individual performed the median number of routines (3.0 routines) they were given the value 1, while an individual performing less than the median number of routines was given the value 0 . Each dichotomized outcome was made a function of the main effects (depression, FCC, coping, social support, and ethnicity) as well as all of the two-way interactions with depression to evaluate whether depression independently 
predicted each outcome after adjustment. All data were analyzed using SAS $®$ [Version 9.3; Cary, NC, USA]. Prior to the initiation of the study, an institutional review board determined that the study was exempt. No corrections (e.g., Bonferroni) were made for multiple testing, since we felt each outcome was important in isolation.

\section{Results}

A total of $\mathrm{N}=2063$ were included in the analysis $(n=1562,75.7 \%$ not depressed, $n=$ $501,24.3 \%$ depressed). There was no difference in demographic variables between those who reported depressive symptoms and those who did not (Table 1). Depression was significantly correlated with only one other predictor, which was how well he/she coped with the demands of parenthood. Depression was inversely related to coping well with the demands of parenthood $(r$ $=-0.455, p=0.020)$

\section{Influence of Depression on Outcomes}

Depressive symptomology significantly decreased the odds that an individual performed more than the median number of routines $(\mathrm{OR}=0.68,95 \% \mathrm{CI} 0.54-0.82, p=0.018)$ and increased the odds that an individual performed more than the median number of punitive behaviors $(\mathrm{OR}=1.51,95 \% \mathrm{CI} 1.15-1.92, p=0.007)$. This suggests that these relationships were not mediated by FCC.

\section{Influence of FCC on Outcomes}

FCC independently and significantly increased the odds that an individual performed more than the median number of routines $(\mathrm{OR}=1.12,95 \% \mathrm{CI} 1.03-1.23, p=0.011)$.

\section{Other Influences on Outcomes}

Coping $(\mathrm{OR}=0.23,95 \% \mathrm{CI} 0.08-0.40, \mathrm{p}<0.001)$ and social support $(\mathrm{OR}=0.17,95 \% \mathrm{CI}$ 0.03-0.39, $p<0.001)$ decreased the odds that an individual performed more than the median 
number of punitive behaviors. Coping ( $\mathrm{OR}=1.54,95 \% \mathrm{CI} 1.30-1.70, p<0.001)$ and social support $(\mathrm{OR}=1.37,95 \% \mathrm{CI} 1.14-1.68, p<0.001)$ increased the odds that an individual performed more than the median number of positive disciplinary strategies. No significant interaction effects existed between depression and any other variable studied (FCC, coping, social support, or ethnicity). That is, the relationship between the presence of depressive symptoms and each outcome was not moderated by another predictor."

\section{Discussion}

Parental depression is frequently encountered by pediatricians and pediatric nurse practitioners; yet, limited primary care-based interventions aimed specifically at this health risk group exist in the outpatient setting. This study sought to examine whether providing FCC lessens the association of suboptimal parenting behaviors among caregivers with depressive symptoms and builds upon previously published findings from the NSECH dataset by Regalado et al.(Regalado et al., 2004). We found that despite parents' receipt of FCC, those with depressive symptoms continued to use punitive disciplinary behaviors and institute fewer routines (regularity of mealtime, naptime, and bedtime).

Family-centered care is an approach to engage families and is considered the standard of pediatric practice (Committee on Hospital Care and Institute for Patient- and Family-Centered Care, 2012; National Association of Pediatric Nurse Practitioners' Health Policy Committee, 2015). Little exists in the literature examining the effect FCC has on the behaviors of mothers with depressive symptoms or what specific aspects of FCC might be associated with more positive parenting behaviors. It is unclear why FCC did not moderate the effects of depression on our outcome variables. The study used parents' report about whether they received FCC. Each question referred to their experience within the past year. It is not clear whether the parent was 
accurate in his/her recall. Additionally, family-centered care may need to be operationalized differently in future studied to determine what specific provider behaviors may help to moderate the effects of depression on parenting behaviors.

When parental depression is suspected during well-child visits, pediatric providers may suggest any number of recommendations including lifestyle changes, involvement of family members, scheduling more time with the health care provider, or referral to self-help or support groups or to mental health professionals (Olson et al., 2002). However, little is known about whether parents with depressive symptoms actually follow through with recommendations given to them.

Our study specifically found that parents with depressive symptoms were less likely to adhere to routines for sleep and meals or advice about childproofing and reading to their children. These mothers also reported more difficulties coping with parenting demands and were more likely to use punitive parenting strategies. Our findings support those of other studies that have examined the association between maternal depressive symptoms and parenting practices from birth to entry into kindergarten (Kavanaugh et al., 2006; McLearn, Minkovitz, Strobino, Marks, \& Hou, 2006a, 2006b; Paulson \& Bazemore, 2010). It highlights the fact that it is not uncommon for parents with young children to report depressive symptoms that affect their ability to carry out critical parenting behaviors central to children's health and wellbeing. Important to note, however, the presence of depressive symptoms was not associated with differences in all parenting behaviors. For example, the presence of depressive symptoms was related to the use of fewer routines (bed time, nap time, and meal time), but not with the family eating breakfast or dinner together. Likewise, only reading to the child differed between those with and without depressive symptoms, but singing/listening to music and going on outings did 
not. Both measures of punitive behavior was associated with depression, but only one of the three positive disciplinary strategies (explaining that child behavior is wrong) differed. Lastly, only one of the measures of safety or childproofing differed, which was putting locks on cabinets. So, while the presence of depressive symptoms was associated with differences in positive and negative parenting behaviors, it was not universally so. More data are needed to better understand the burdens that these parenting behaviors may have on parents who have depressive symptoms and how they can be better supported in their role as parents.

Many pediatric health care providers feel it is their responsibility to screen for and intervene when a mother is suspected of having depressive symptoms (Olson et al., 2002). Strong evidence now exists from the science of early brain and child development that exposure to adversities in early childhood, such as maternal depression, leads to alterations in the brain connectivity with implications for lifelong health and development (Bellis, Lowey, Leckenby, Hughes, \& Harrison, 2014; Callender, Olson, Choe, \& Sameroff, 2012; Cambron, Gringeri, \& Vogel-Ferguson, 2014; Cho, Kim, Lim, Lee, \& Shin, 2015; Duncan, Ziol-Guest, \& Kalil, 2010; Escueta, Whetten, Ostermann, O'Donnell, \& Positive Outcomes for Orphans Research, 2014; Ferro \& Boyle, 2015; Jensen, Dumontheil, \& Barker, 2014; Kalmakis \& Chandler, 2014; Kujawa et al., 2014; McCurdy, Gorman, Kisler, \& Metallinos-Katsaras, 2014; Mersky, Topitzes, \& Reynolds, 2013; Montgomery, Cutuli, Evans-Chase, Treglia, \& Culhane, 2013; NICHD Early Child Care Research Network, 1999; Oettinger \& Paulson, 2014; Reiser, McMillan, Wright, \& Asmundson, 2014; Roos et al., 2013; Shonkoff, Richter, van der Gaag, \& Bhutta, 2012; Slykerman et al., 2015; Tissot et al., 2014; Visser et al., 2014). This literature provides evergrowing support for the detrimental effects of parental depression on physical and mental health, behavioral, and cognitive outcomes for children. Clearly, improving the early identification and 
treatment of parental depression as well as other adversities is critical for pediatric primary health care providers. Even though there are validated and brief tools for screening for maternal depression in primary care (J. L. Cox, Holden, \& Sagovsky, 1987; Kroenke, Spitzer, \& Williams, 2001), there is little guidance available to the pediatrician and pediatric nurse practitioner on how to best handle maternal depression once suspected. Moreover, there exist no specific recommendations on timing and how often to screen (American College of Obstetricians and Gynecologists, 2010; Horwitz, Briggs-Gowan, Storfer-Isser, \& Carter, 2007, 2009). Reimbursement for screening for maternal depression is often cited as a barrier to routine screening. However, the Illinois Department of Healthcare and Family Services successfully established statewide maternal depression screening. This model incorporated Medicaid reimbursement for risk assessment screening with the use of three pre-approved standardized instruments for maternal depression, along with a statewide telephone consultation service with a psychiatrist (Illinois Department of Healthcare and Family Services, 2014).

Another known barrier to routine screening is a lack of options to offer mothers if depression is suspected. Supportive watching and brief counseling may be adequate in a majority of cases; however, pediatric providers may be the first to suspect a worsening of symptoms or functioning. Little advice currently exists on how to facilitate two-way communication between the pediatric primary care provider and the mother's primary care provider, obstetrician, or women's health nurse practitioner. There is also a paucity of brief interventions that can be delivered in the primary care setting, specifically, to support depressed mothers, especially those with temporary or mild symptoms. When such interventions are developed, it would be important to include strategies for the busy pediatric provider to gain confidence in his/her initial efforts to intervene. Recent pilot work has demonstrated the feasibility, acceptability, and initial 
efficacy of a group intervention offered in a community health clinic (Valdez, Mills, Barrueco, Leis, \& Riley, 2011; Valdez, Padilla, Moore, \& Magana). Large, randomized clinical trials are needed to further determine the long-term effects of such interventions. Moreover, ongoing work is needed at the policy level to ensure appropriate reimbursement for greater care coordination efforts related to maternal depression.

Pediatric primary care-based interventions to support the family are highly effective (Perrin et al., 2014), but require systems-level changes and resources, which has limited their widespread dissemination thus far. Promotion of positive parenting behavior with all parents has merit, but even more emphasis might be needed in the face of additional risk factors such as parental depression. Additionally, anticipatory guidance is needed to ensure that parents with depressive symptoms develop strategies and support networks to assist them in providing an optimal caregiving environment while the depressive symptoms are being managed. Evidencebased brief interventions such as Reach Out and Read (ROR) are helpful in promoting literacy (Mendelsohn et al., 2001; Weitzman, Roy, Walls, \& Tomlin, 2004) and creating opportunities for the implementation of bedtime routines (High, LaGasse, Becker, Ahlgren, \& Gardner, 2000). Others have shown that providing children's books with positive parenting storylines has been shown to increase caregiver awareness of non-punitive techniques to handle everyday behavior challenges (Bauer et al., 2012; Bauer et al., 2013). For mothers with more severe symptoms and those who are at highest risk, home visitation programs have been shown to produce effective results and long-term cost savings. When these programs are well-coordinated with the medical home (Paradis, Sandler, Manly, \& Valentine, 2013), child health can be optimized.

The study has several limitations. The NSECH uses cross-sectional data from 2000. As such, causation cannot be determined using these cross-sectional data. Additionally, parental 
depression was measured by self-report of depressive symptoms rather than using an objective measure of depression, which introduces the potential for social desirability bias.

In summary, more work needs to be done to help pediatricians and pediatric nurse practitioners in primary care settings to identify the presence of parental depressive symptoms and intervene early. New models of care that provide greater access to mental health professionals for consultative services may be helpful and cost-effective. For a majority of families, having a medical home and receiving FCC increases the likelihood parents will adhere to anticipatory guidance that optimizes positive child outcomes. Parents with depressive symptoms require additional intervention and support. Effective large-scale programs exist, but they are not universal or widely disseminated. More data and guidance are needed to help pediatric primary care providers to identify, stratify, and support parents with depressive symptoms. 


\section{References}

American College of Obstetricians and Gynecologists. (2010). Screening for depression during and after pregnancy: Committee Opinion No. 453. Obstetrics and Gynecology, 115, 394395. doi: 10.1097/aog.0b013e3181d035aa

Bauer, N. S., Hus, A. M., Sullivan, P. D., Szczepaniak, D., Carroll, A. E., \& Downs, S. M. (2012). A pilot study using children's books to understand caregiver perceptions of parenting practices. Journal of Developmental and Behavioral Pediatrics, 33(5), 423430. doi: $10.1097 / \mathrm{dbp} .0 \mathrm{~b} 013 \mathrm{e} 3182560 \mathrm{~d} 87$

Bauer, N. S., Stanton, J. L., Carroll, A., E., \& Downs, S. M. (2013). Children's books as a brief intervention for parents with depressive symptoms and parenting stress. Journal of Behavioral Health, 2(4), 318-325. doi: 10.5455/jbh.20130822051604

Beardslee, W. R., Gladstone, T. R., Wright, E. J., \& Cooper, A. B. (2003). A family-based approach to the prevention of depressive symptoms in children at risk: evidence of parental and child change. Pediatrics, 112(2), e119-131. doi: 10.1542/peds.112.2.e119

Bellis, M. A., Lowey, H., Leckenby, N., Hughes, K., \& Harrison, D. (2014). Adverse childhood experiences: retrospective study to determine their impact on adult health behaviours and health outcomes in a UK population. Journal of Public Health, 36(1), 81-91. doi: 10.1093/pubmed/fdt038

Belsky, J., \& Jaffee, S. R. (2006). The multiple determinants of parenting. In D. Cicchetti \& D. J. Cohen (Eds.), Developmental psychopathology, Vol 3: Risk, disorder, and adaptation (2nd ed.) (pp. 38-85). Hoboken, NJ: John Wiley \& Sons Inc.

Belsky, J., \& Pluess, M. (2009). The nature (and nurture?) of plasticity in early human development. Perspectives on Psychological Science, 4, 345-351. 
Berkule, S. B., Cates, C. B., Dreyer, B. P., Huberman, H. S., Arevalo, J., Burtchen, N., . . . Mendelsohn, A. L. (2014). Reducing maternal depressive symptoms through promotion of parenting in pediatric primary care. Clinical Pediatrics, 53(5), 460-469. doi: $10.1177 / 0009922814528033$

Berwick, D. M., Murphy, J. M., Goldman, P. A., Ware, J. E., Jr., Barsky, A. J., \& Weinstein, M. C. (1991). Performance of a five-item mental health screening test. Medical Care, 29(2), 169-176. doi: 10.1097/00005650-199102000-00008

Blumberg, S. J., \& O'Connor, K. S. (2004). Parents' mood and the content of pediatric care for young children. Ambulatory Pediatrics, 4(3), 209-216. doi: http://dx.doi.org/10.1367/A03-127-R.1

Blumberg, S. J., Olson, L., \& Osborn, L. (2002). Design and operation of the National Survey of Early Childhood Health, 2000. In V. H. S. National Center for Health Statistics (Ed.), (Vol. 1). Hyattsville, MD: Department of Health and Human Services, Centers for Disease Control and Prevention, National Center for Health Statistics.

Bradley, R. H. (2002). Environment and parenting. Mahwah, NJ: Lawrence Erlbaum Associates Publishers.

Callender, K. A., Olson, S. L., Choe, D. E., \& Sameroff, A. J. (2012). The effects of parental depressive symptoms, appraisals, and physical punishment on later child externalizing behavior.[Erratum appears in J Abnorm Child Psychol. 2012 Apr;40(3):485]. Journal of Abnormal Child Psychology, 40(3), 471-483.

Cambron, C., Gringeri, C., \& Vogel-Ferguson, M. B. (2014). Physical and mental health correlates of adverse childhood experiences among low-income women. Health and Social Work, 39(4), 221-229. doi: 10.1093/hsw/hlu029 
Campbell, S. B., Matestic, P., von Stauffenberg, C., Mohan, R., \& Kirchner, T. (2007).

Trajectories of maternal depressive symptoms, maternal sensitivity, and children's functioning at school entry. Developmental Psychology, 1202-1215. doi: 10.1037/00121649.43 .5 .1202

Cho, S.-M., Kim, E., Lim, K.-Y., Lee, J.-W., \& Shin, Y.-M. (2015). The effects of maternal depression on child mental health problems based on gender of the child. Community Mental Health Journal, 51(3), 354-358. doi: 10.1007/s10597-014-9824-6

Chronis, A. M., Lahey, B. B., Pelham, W. E., Jr., Williams, S. H., Baumann, B. L., Kipp, H., . . Rathouz, P. J. (2007). Maternal depression and early positive parenting predict future conduct problems in young children with attention-deficit/hyperactivity disorder. Developmental Psychology, 43(1), 70-82.

Clare, C. A., \& Yeh, J. (2012). Postpartum depression in special populations: A review. Obstetrical and Gynecological Survey, 67(5), 313-323. doi: 10.1097/ogx.0b013e318259cb52

Committee on Hospital Care and Institute for Patient- and Family-Centered Care. (2012). Patient- and Family-Centered Care and the Pediatrician's Role. Pediatrics, 129, 394-404. doi: doi: 10.1542/peds.2011-3084

Committee on Hospital Care Institute for Patient- and Family-Centered Care. (2012). Patientand Family-Centered Care and the pediatrician's role. Pediatrics. doi: 10.1542/peds.20113084

Cornish, A., McMahon, C., Ungerer, J., Barnett, B., Kowalenko, N., \& Tennant, C. (2005). Postnatal depression and infant cognitive and motor development in the second postnatal 
year: The impact of depression chronicity and infant gender. Infant Behavior \& Development, 28, 407-417. doi: 10.1016/j.infbeh.2005.03.004

Cox, J. E., Buman, M. P., Woods, E. R., Famakinwa, O., \& Harris, S. K. (2012). Evaluation of raising adolescent families together program: A medical home for adolescent mothers and their children. American Journal of Public Health, 102(10), 1879-1885. doi: 10.2105/ajph.2012.300766

Cox, J. L., Holden, J. M., \& Sagovsky, R. (1987). Detection of postnatal depression. Development of the 10-item Edinburgh Postnatal Depression Scale. British Journal of Psychiatry, 150, 782-786. doi: 10.1192/bjp.150.6.782

de Graaf, I., Speetjens, P., Smit, F., de Wolff, M., \& Tavecchio, L. (2008a). Effectiveness of the Triple P Positive Parenting Program on behavioral problems in children: A meta-analysis. Behavior Modification, 32(5), 714-735.

de Graaf, I., Speetjens, P., Smit, F., de Wolff, M., \& Tavecchio, L. (2008b). Effectiveness of the Triple P Positive Parenting Program on parenting: A meta-analysis. Family Relations: An Interdisciplinary Journal of Applied Family Studies, 57(5), 553-566.

DeVries, A., Li, C. H., Sridhar, G., Hummel, J. R., Breidbart, S., \& Barron, J. J. (2012). Impact of medical homes on quality, healthcare utilization, and costs. American Journal of Managed Care, 18(9), 534-544.

Dilworth-Bart, J. E., Khurshid, A., \& Vandell, D. L. (2007). Do maternal stress and home environment mediate the relation between early income-to-need and 54-months attentional abilities? Infant and Child Development, 16, 525-552. 
Duncan, G. J., Ziol-Guest, K. M., \& Kalil, A. (2010). Early-childhood poverty and adult attainment, behavior, and health. Child Development, 81(1), 306-325. doi: 10.1111/j.1467-8624.2009.01396.x

Earls, M. F., \& The Committee on Psychosocial Aspects of Child and Family Health. (2010). Incorporating recognition and management of perinatal and postpartum depression into pediatric practice. Pediatrics, 126(5), 1032-1039. doi: 10.1542/peds.2010-2348

Escueta, M., Whetten, K., Ostermann, J., O'Donnell, K., \& Positive Outcomes for Orphans Research, T. (2014). Adverse childhood experiences, psychosocial well-being and cognitive development among orphans and abandoned children in five low income countries. BMC International Health and Human Rights, 14, 6. doi: 10.1186/1472-698X14-6

Ferro, M., \& Boyle, M. (2015). The impact of chronic physical illness, maternal depressive symptoms, family functioning, and self-esteem on symptoms of anxiety and depression in children. Journal of Abnormal Child Psychology, 43(1), 177-187. doi: 10.1007/s10802014-9893-6

Field, T. (1998). Maternal depression effects on infants and early interventions. Preventive Medicine, 27(2), 200-203. doi: 10.1006/pmed.1998.0293

Fletcher, R. J., Feeman, E., Garfield, C., \& Vimpani, G. (2011). The effects of early paternal depression on children's development. Medical Journal of Australia, 195(11-12), 685689. doi: $10.5694 / \mathrm{mja1} 1.10192$

Gartstein, M. A., \& Fagot, B. I. (2003). Parental depression, parenting and family adjustment, and child effortful control: Explaining externalizing behaviors for preschool children. Applied Developmental Psychology, 24, 143-177. doi: 10.1016/s0193-3973(03)00043-1 
Heneghan, A. M., Silver, E. J., Bauman, L. J., Westbrook, L. E., \& Stein, R. E. (1998).

Depressive symptoms in inner-city mothers of young children: who is at risk? Pediatrics, 102(6), 1394-1400. doi: 10.1542/peds.102.6.1394

High, P. C., LaGasse, L., Becker, S., Ahlgren, I., \& Gardner, A. (2000). Literacy promotion in primary care pediatrics: Can we make a difference? Pediatrics, 105(4 Pt 2), 927-934. doi: 10.1097/00004703-199910000-00046

Horwitz, S. M., Briggs-Gowan, M. J., Storfer-Isser, A., \& Carter, A. S. (2007). Prevalence, correlates, and persistence of maternal depression. Journal of Women's Health, 16(5), 678-691. doi: 10.1089/jwh.2008.1229

Horwitz, S. M., Briggs-Gowan, M. J., Storfer-Isser, A., \& Carter, A. S. (2009). Persistence of maternal depressive symptoms throughout the early years of childhood. Journal of Women's Health, 18(5), 637-645. doi: 10.1089/jwh.2008.1229

Illinois Department of Healthcare and Family Services. (2014). Maternal and Child Health Promotion: Perinatal Depression. Retrieved February 10, 2015, from http://www2.illinois.gov/hfs/MedicalProvider/MaternalandChildHealthPromotion/Pages/ $\underline{\text { default.aspx }}$

Jensen, S. K. G., Dumontheil, I., \& Barker, E. D. (2014). Developmental inter-relations between early maternal depression, contextual risks, and interpersonal stress, and their effect on later child cognitive functioning. Depression \& Anxiety (1091-4269), 31(7), 599-607. doi: $10.1002 /$ da. 22147

Juffers, F., Bakersmans-Kraneburg, M. J., \& Van Ijzendoorn, M. H. (2008a). Promoting positive parenting: An attachment-based intervention. New York: Taylor \& Francis. 
Juffers, F., Bakersmans-Kraneburg, M. J., \& Van Ijzendoorn, M. H. (2008b). Promoting positive parenting: An introduction. In F. Juffers, M. J. Bakersmans-Kraneburg, \& M. H. Van Ijzendoorn (Eds.), Promoting positive parenting: An attachment-based intervention. New York: Taylor \& Francis.

Kalmakis, K. A., \& Chandler, G. E. (2014). Adverse childhood experiences: towards a clear conceptual meaning. Journal of Advanced Nursing, 70(7), 1489-1501. doi: 10.1111/jan.12329

Kavanaugh, M., Halterman, J. S., Montes, G., Epstein, M., Hightower, A. D., \& Weitzman, M. (2006). Maternal depressive symptoms are adversely associated with prevention practices and parenting behaviors for preschool children. Ambulatory Pediatrics, 6(1), 32-37. doi: 10.1016/j.ambp.2005.09.002

Kelly, M. J., Dunstan, F. D., Lloyd, K., \& Fone, D. L. (2008). Evaluating cutpoints for the MHI5 and MCS using the GHQ-12: A comparison of five different methods. BMC Psychiatry, 8, 10. doi: 10.1186/1471-244x-8-10

Kogan, M. D., Schuster, M. A., Yu, S. M., Park, C. H., Olson, L. M., Inkelas, M., . . Halfon, N. (2004). Routine assessment of family and community health risks: parent views and what they receive [Erratum appears in Pediatrics. 2005 Sep;116(3):802]. Pediatrics, 113(6 Suppl), 1934-1943.

Kroenke, K., Spitzer, R. L., \& Williams, J. B. (2001). The PHQ-9: validity of a brief depression severity measure. Journal of General Internal Medicine, 16(9), 606-613. doi: 10.1046/j.1525-1497.2001.016009606.x

Kujawa, A., Dougherty, L. E. A., Durbin, C. E., Laptook, R., Torpey, D., \& Klein, D. N. (2014). Emotion recognition in preschool children: Associations with maternal depression and 
early parenting. Development and Psychopathology, 26(1), 159-170. doi: $10.1017 / \mathrm{S} 0954579413000928$

Kurstjens, S., \& Wolke, D. (2001). Effects of maternal depression on cognitive development of children over the first 7 years of life. Journal of Child Psychology and Psychiatry and Allied Disciplines, 42, 623-636. doi: 10.1111/1469-7610.00758

Landry, S. H., \& Smith, K. E. (2011). Maternal sensitivity and responsiveness: A conceptual framework with empirical evidence. In D. W. Davis \& M. C. Logsdon (Eds.), Maternal sensitivity: A foundation for clinical practice. New York, NY: Nova Science Publishers, Inc.

Landry, S. H., Smith, K. E., \& Swank, P. R. (2006). Responsive parenting: Establishing early foundations for social, communication, and independent problem-solving skills. Developmental Psychology, 42, 627-642.

Landry, S. H., Smith, K. E., Swank, P. R., \& Guttentag, C. (2008). A responsive parenting intervention: The optimal timing across early childhood for impacting maternal behaviors and child outcomes. Developmental Psychology, 44, 1335-1353.

Leiferman, J. A., Ollendick, T. H., Kunkel, D., \& Christie, I. C. (2005). Mothers' mental distress and parenting practices with infants and toddlers. Archives of Women's Mental Health, 8(4), 243-247. doi: 10.1007/s00737-005-0098-4

Logsdon, M. C., Mcbride, A. G., \& Birkimer, J. C. (1994). Social support and postpartum depression. Research in Nursing and Health, 17, 449-457. doi: 10.1002/nur.4770170608

Logsdon, M. C., Wisner, K., \& Pinto-Foltz, M. (2006). The impact of postpartum depression on mothering. Journal of Obstretrics, Gynecology, and Neonatal Nursing (JOGNN), 35, 652-658. doi: 10.1111/J.1552-6909.2006.00087 
Long, W. E., Bauchner, H., Sege, R. D., Cabral, H. J., \& Garg, A. (2012). The value of the medical home for children without special health care needs. Pediatrics, 129(1), 87-98. doi: 10.1542/peds.2011-1739d

Matheny, A. P., Wachs, T. D., Ludwig, J. L., \& Phillips, K. (1995). Bringing order out of chaos: Psychometric characteristics of the Confusion, Hubbub, and Order Scale. Journal of Applied Developmental Psychology, 16, 429-444.

Matsumoto, Y., Sofronoff, K., \& Sanders, M. R. (2010). Investigation of the effectiveness and social validity of the Triple P Positive Parenting Program in Japanese society. Journal of Family Psychology, 24(1), 87-91.

Maughan, A., Cicchetti, D., Toth, S. L., \& Rogosch, F. A. (2007). Early-occurring maternal depression and maternal negativity in predicting young children's emotion regulation and socioemotional difficulties. Journal of Abnormal Child Psychology, 35(5), 685-703. doi: $10.1007 / \mathrm{s} 10802-007-9129-0$

McCurdy, K., Gorman, K. S., Kisler, T., \& Metallinos-Katsaras, E. (2014). Associations between family food behaviors, maternal depression, and child weight among low-income children. Appetite, 79, 97-105. doi: 10.1016/j.appet.2014.04.015

McHorney, C. A., \& Ware, J. E., Jr. (1995). Construction and validation of an alternate form general mental health scale for the Medical Outcomes Study Short-Form 36-Item Health Survey. Medical Care, 33(1), 15-28. doi: 10.1097/00005650-199501000-00002

McHorney, C. A., Ware, J. E., Jr., Lu, J. F., \& Sherbourne, C. D. (1994). The MOS 36-item Short-Form Health Survey (SF-36): III. Tests of data quality, scaling assumptions, and reliability across diverse patient groups. Medical Care, 32(1), 40-66. doi:

10.1097/00005650-199401000-00004 
McHorney, C. A., Ware, J. E., Jr., \& Raczek, A. E. (1993). The MOS 36-Item Short-Form Health Survey (SF-36): II. Psychometric and clinical tests of validity in measuring physical and mental health constructs. Medical Care, 31(3), 247-263. doi:

10.1097/00005650-199303000-00006

McHorney, C. A., Ware, J. E., Jr., Rogers, W., Raczek, A. E., \& Lu, J. F. (1992). The validity and relative precision of MOS short- and long-form health status scales and Dartmouth COOP charts. Results from the Medical Outcomes Study. Medical Care, 30(5 Suppl), MS253-265. doi: 10.1097/00005650-199205001-00025

McLearn, K. T., Minkovitz, C. S., Strobino, D. M., Marks, E., \& Hou, W. (2006a). Maternal depressive symptoms at 2 to 4 months post partum and early parenting practices. Archives of Pediatrics and Adolescent Medicine, 160(3), 279-284. doi: 10.1001/archpedi.160.3.279

McLearn, K. T., Minkovitz, C. S., Strobino, D. M., Marks, E., \& Hou, W. (2006b). The timing of maternal depressive symptoms and mothers' parenting practices with young children: implications for pediatric practice. Pediatrics, 118(1), e174-182. doi: 10.1542/peds.20051551

Mendelsohn, A. L., Mogilner, L. N., Dreyer, B. P., Forman, J. A., Weinstein, S. C., Broderick, M., .. . Napier, C. (2001). The impact of a clinic-based literacy intervention on language development in inner-city preschool children. Pediatrics, 107(1), 130-134. doi: 10.1542/peds.107.1.130

Mersky, J. P., Topitzes, J., \& Reynolds, A. J. (2013). Impacts of adverse childhood experiences on health, mental health, and substance use in early adulthood: a cohort study of an 
urban, minority sample in the U.S. Child Abuse and Neglect, 37(11), 917-925. doi: 10.1016/j.chiabu.2013.07.011

Mistry, R., Stevens, G. D., Sareen, H., De Vogli, R., \& Halfon, N. (2007). Parenting-related stressors and self-reported mental health of mothers with young children.[Erratum appears in Am J Public Health. 2007 Sep;97(9):1543]. American Journal of Public Health, 97(7), 1261-1268. doi: 10.2105/ajph.2006.088161

Montgomery, A. E., Cutuli, J. J., Evans-Chase, M., Treglia, D., \& Culhane, D. P. (2013). Relationship among adverse childhood experiences, history of active military service, and adult outcomes: homelessness, mental health, and physical health. American Journal of Public Health, 103 Suppl 2, S262-268. doi: 10.2105/ajph.2013.301474

Morrongiello, B. A., \& Kiriakou, S. (2004). Mothers' home-safety practices for preventing six types of childhood injuries: What do they do, and why? Journal of Pediatric Psychology, 29(4), 285-297.

Mulvaney, M. K., \& Mebert, C. J. (2010). Stress appraisal and attitudes towards corporal punishment as intervening processes between corporal punishment and subsequent mental health. Journal of Family Violence, 25(4), 401-412.

National Association of Pediatric Nurse Practitioners' Health Policy Committee. (2015). Health Policy Agenda. Retrieved February 10, 2015, from https://www.napnap.org/healthpolicy-agenda

National Institute for Health Care Management. (2010). Identifying and treating maternal depression: Strategies \& considerations for health plans Washington, DC: National Institute for Health Care Management Foundation. 
NICHD Early Child Care Research Network. (1999). Chronicity of maternal depressive symptoms, maternal sensitivity, and child functioning. Developmental Psychology, 35, 1297-1310. doi: 10.1037//0012-1649.35.5.1297

Nowak, C., \& Heinrichs, N. (2008). A comprehensive meta-analysis of Triple P-Positive Parenting Program using hierarchical linear modeling: Effectiveness and moderating variables. Clinical Child and Family Psychology Review, 11(3), 114-144. doi: $10.1007 / \mathrm{s} 10567-008-0033-0$

Oettinger, E., \& Paulson, J. (2014). Effects of early maternal postpartum depression on child executive functioning. Archives of Clinical Neuropsychology, 29(6), 549-549.

Olson, A. L., Kemper, K. J., Kelleher, K. J., Hammond, C. S., Zuckerman, B. S., \& Dietrich, A. J. (2002). Primary care pediatricians' roles and perceived responsibilities in the identification and management of maternal depression. Pediatrics, 110(6), 1169-1176. doi: $10.1542 /$ peds.110.6.1169

Paradis, H. A., Sandler, M., Manly, J. T., \& Valentine, L. (2013). Building healthy children: Evidence-based home visitation integrated with pediatric medical homes. Pediatrics, 132 Suppl 2, S174-179. doi: 10.1542/peds.2013-1021r

Paulson, J. F., \& Bazemore, S. D. (2010). Prenatal and postpartum depression in fathers and its association with maternal depression: A meta-analysis. JAMA, 303(19), 1961-1969. doi: 10.1001/jama.2010.605

Perrin, E. C., Sheldrick, R., McMenamy, J. M., Henson, B. S., \& Carter, A. S. (2014). Improving parenting skills for families of young children in pediatric settings: A randomized clinical trial. JAMA Pediatrics, 168(1), 16-24. doi: 10.1001/jamapediatrics.2013.2919 
Petterson, S. M., \& Albers, A. B. (2001). Effects of poverty and maternal depression on early child development. Child Development, 72(6), 1794-1813. doi: 10.1111/14678624.00379

Ramchandani, P. G., Psychogiou, L., Vlachos, H., Iles, J., Sethna, V., Netsi, E., \& Lodder, A. (2011). Paternal depression: An examination of its links with father, child and family functioning in the postnatal period. Depression and Anxiety, 28(6), 471-477. doi: $10.1002 /$ da. 20814

Ramchandani, P. G., Stein, A., Evans, J., O'Connor, T. G., \& Alspac study team. (2005). Paternal depression in the postnatal period and child development: A prospective population study. Lancet, 365(9478), 2201-2205. doi: 10.1002/da.20814

Regalado, M., Sareen, H., Inkelas, M., Wissow, L. S., \& Halfon, N. (2004). Parents' discipline of young children: results from the National Survey of Early Childhood Health. Pediatrics, 113(6 Suppl), 1952-1958.

Reiser, S. J., McMillan, K. A., Wright, K. D., \& Asmundson, G. J. (2014). Adverse childhood experiences and health anxiety in adulthood. Child Abuse and Neglect, 38(3), 407-413. doi: 10.1016/j.chiabu.2013.08.007

Romaire, M. A., Bell, J. F., \& Grossman, D. C. (2012). Medical home access and health care use and expenditures among children with special health care needs. Archives of Pediatrics and Adolescent Medicine, 166(4), 323-330. doi: 10.1001/archpediatrics.2011.1154

Roos, L. E., Mota, N., Afifi, T. O., Katz, L. Y., Distasio, J., \& Sareen, J. (2013). Relationship between adverse childhood experiences and homelessness and the impact of axis I and II disorders. American Journal of Public Health, 103 Suppl 2, S275-281. doi:

10.2105/ajph.2013.301323 
Sanders, M. R., Bor, W., \& Morawska, A. (2007). Maintenance of treatment gains: a comparison of enhanced, standard, and self-directed Triple P-Positive Parenting Program. Journal of Abnormal Child Psychology, 35(6), 983-998.

Santos, I. S., Matijasevich, A., Domingues, M. R., Barros, A. J., \& Barros, F. C. (2010). Longlasting maternal depression and child growth at 4 years of age: a cohort study. Journal of Pediatrics, 157(3), 401-406. doi: 10.1016/j.jpeds.2010.03.008

Shonkoff, J. P. (2010). Building a new biodevelopmental framework to guide the future of early childhood policy. Child Development, 81(1), 357-367.

Shonkoff, J. P., Garner, A. S., Committee on Psychosocial Aspects of Child and Family Health, Committee on Early Childhood Adoption and Dependent Care, Section on Developmental Behavioral Pediatrics, Siegel, B. S., . . Wood, D. L. (2012). The lifelong effects of early childhood adversity and toxic stress. Pediatrics, 129(1), e232-e246. doi: 10.1542/peds.2011-2663

Shonkoff, J. P., Richter, L., van der Gaag, J., \& Bhutta, Z. A. (2012). An Integrated Scientific Framework for Child Survival and Early Childhood Development. Pediatrics, 129(2), e460-e472. doi: 10.1542/peds.2011-0366

Slykerman, R. F., Thompson, J., Waldie, K., Murphy, R., Wall, C., \& Mitchell, E. A. (2015). Maternal stress during pregnancy is associated with moderate to severe depression in 11year-old children. Acta Paediatrica, 104(1), 68-74. doi: 10.1111/apa.12787

Spijkers, W., Jansen, D. E., de Meer, G., \& Reijneveld, S. A. (2010). Effectiveness of a parenting programme in a public health setting: a randomised controlled trial of the positive parenting programme (Triple P) level 3 versus care as usual provided by the preventive child healthcare (PCH). BMC Public Health, 10, 131. 
Tamis-LeMonda, C. S., \& Baumwell, L. (2011). Parental sensitivity in early development; Definitions, methods, measurement, and generalizability. In D. W. Davis \& M. C. Logsdon (Eds.), Maternal sensitivity: A foundation for practice (pp. 1-15). New York, NY: Nova Science Publishers, Inc.

Teti, D. M., O'Connell, M. A., \& Reiner, C. D. (1996). Parenting sensitivity, parental depression and child health: The mediational role of parental self-efficacy. Early Development and Parenting, 5(4), 237-250. doi: 10.1002/(SICI)1099-0917(199612)5:4<237::AIDEDP136>3.0.CO;2-5

Thomas, R., \& Zimmer-Gembeck, M. J. (2007). Behavioral outcomes of Parent-Child Interaction Therapy and Triple P-Positive Parenting Program: A review and meta-analysis. Journal of Abnormal Child Psychology, 35(3), 475-495.

Tissot, H., Scaiola, C. L., Frascarolo, F., Despland, J.-N., Stiefel, F., \& Favez, N. (2014). Family alliance as a moderator of the link between maternal postpartum depression and child symptoms assessed by both parents. Journal of Family Issues, 35(11), 1520-1542. doi: $10.1177 / 0192513 \times 13488522$

Tronick, E., \& Reck, C. (2009). Infants of depressed mothers. Harvard Review of Psychiatry, 17(2), 147-156. doi: 10.1080/10673220902899714

Valdez, C. R., Mills, C. L., Barrueco, S., Leis, J., \& Riley, A. W. (2011). A pilot study of a family-focused intervention for children and families affected by maternal depression. Journal of Family Therapy, 33(1), 3-19. doi: 10.1111/j.1467-6427.2010.00529.x

Valdez, C. R., Padilla, B., Moore, S. M., \& Magana, S. Feasibility, acceptability, and preliminary outcomes of the Fortalezas Familiares intervention for Latino families facing maternal depression. Family Process, 52(3), 394-410. 
Vanderveen, J. A., Bassler, D., Robertson, C. M. T., \& Kirpalani, H. (2009). Early interventions involving parents to improve neurodevelopmental outcomes of premature infants: a metaanalysis. Journal of Perinatology, 29, 343-351.

Viguera, A. C., Tondo, L., Koukopoulos, A. E., Reginaldi, D., Lepri, B., \& Baldessarini, R. J. (2011). Episodes of mood disorders in 2,252 pregnancies and postpartum periods. American Journal of Psychiatry, 168(11), 1179-1185. doi:

10.1176/appi.ajp.2011.11010148

Visser, H. A., van Minnen, A., van Megen, H., Eikelenboom, M., Hoogendoorn, A. W., Kaarsemaker, M., . . . van Oppen, P. (2014). The relationship between adverse childhood experiences and symptom severity, chronicity, and comorbidity in patients with obsessive-compulsive disorder. Journal of Clinical Psychiatry, 75(10), 1034-1039. doi: 10.4088/jcp. $13 \mathrm{~m} 08825$

Wachs, T. (1993). Nature of relations between the physical and social microenvironment of the two-year-old child. Early Development and Parenting, 2(2), 81-87.

Wang, L., Wu, T., Anderson, J. L., \& Florence, J. E. (2011). Prevalence and risk factors of maternal depression during the first three years of child rearing. Journal of Women's Health, 20(5), 711-718. doi: 10.1089/jwh.2010.2232

Weitzman, C. C., Roy, L., Walls, T., \& Tomlin, R. (2004). More evidence for Reach Out and Read: A home-based study. Pediatrics, 113(5), 1248-1253. doi: 10.1542/peds.113.5.1248

Wiggins, T. L., Sofronoff, K., \& Sanders, M. R. (2009). Pathways Triple P-positive parenting program: effects on parent-child relationships and child behavior problems. Family Process, 48(4), 517-530. 
Yonkers, K. A., Vigod, S., \& Ross, L. E. (2011). Diagnosis, pathophysiology, and management of mood disorders in pregnant and postpartum women. Obstetrics and Gynecology, 117(4), 961-977. doi: 10.1097/AOG.0b013e31821187a7 
Table 1

Demographics by Depressive Symptoms Group

\begin{tabular}{|c|c|c|c|c|}
\hline Variable & $\begin{array}{c}\text { Overall } \\
\mathrm{N}=2063(\%)\end{array}$ & $\begin{array}{l}\text { Not Depressed } \\
\mathrm{N}=1562(\%)\end{array}$ & $\begin{array}{c}\text { Depressed } \\
\mathrm{N}=501(\%)\end{array}$ & $p$ \\
\hline Child ever received WIC benefits & $1178(57.1 \%)$ & $845(54.1 \%)$ & $324(64.6 \%)$ & 0.205 \\
\hline Child currently receives WIC benefits & $536(26.0 \%)$ & $370(23.7 \%)$ & $159(31.7 \%)$ & 0.235 \\
\hline \multicolumn{5}{|l|}{ Children in home $<18$ years old } \\
\hline 1 & $446(21.6 \%)$ & $353(22.6 \%)$ & $95(19.0 \%)$ & \multirow{4}{*}{0.911} \\
\hline 2 & $908(44.0 \%)$ & $676(43.3 \%)$ & $228(45.6 \%)$ & \\
\hline 3 & $522(25.3 \%)$ & $395(25.3 \%)$ & $127(25.3 \%)$ & \\
\hline 4 & $190(9.2 \%)$ & $137(8.8 \%)$ & $51(10.1 \%)$ & \\
\hline \multicolumn{5}{|l|}{ Number of children $<3$ years old } \\
\hline 1 & $1828(88.6 \%)$ & $1384(88.6 \%)$ & $444(88.6 \%)$ & \multirow[t]{3}{*}{0.645} \\
\hline 2 & $219(10.6 \%)$ & $161(10.3 \%)$ & $57(11.4 \%)$ & \\
\hline 3 & $14(0.7 \%)$ & $16(1.0 \%)$ & $0(0.0 \%)$ & \\
\hline \multicolumn{5}{|l|}{ Relationship to child } \\
\hline Mother & $1935(93.8 \%)$ & $1450(92.8 \%)$ & $482(96.2 \%)$ & \multirow[t]{3}{*}{0.151} \\
\hline Father & $99(4.8 \%)$ & $97(6.2 \%)$ & $7(1.3 \%)$ & \\
\hline Grandparent & $31(1.5 \%)$ & $16(1.0 \%)$ & $13(2.5 \%)$ & \\
\hline \multicolumn{5}{|l|}{ Mother's marital status } \\
\hline Married & $1331(64.5 \%)$ & $1023(65.5 \%)$ & $311(62.0 \%)$ & \multirow[t]{5}{*}{0.439} \\
\hline Divorced & $128(6.2 \%)$ & $89(5.7 \%)$ & $38(7.6 \%)$ & \\
\hline Separated & $60(2.9 \%)$ & $33(2.1 \%)$ & $26(5.1 \%)$ & \\
\hline Never Married & $522(25.3 \%)$ & $403(25.8 \%)$ & $120(24.0 \%)$ & \\
\hline Other & $23(1.1 \%)$ & $14(0.9 \%)$ & $7(1.3 \%)$ & \\
\hline \multicolumn{5}{|l|}{ Mother's ethnicity } \\
\hline Non-Hispanic, White & $818(39.6 \%)$ & $626(40.1 \%)$ & $192(38.3 \%)$ & \multirow[t]{4}{*}{0.198} \\
\hline Hispanic & $728(35.2 \%)$ & $576(36.9 \%)$ & $152(30.3 \%)$ & \\
\hline Black & $468(22.7 \%)$ & $344(22.0 \%)$ & $124(24.8 \%)$ & \\
\hline Other & $52(2.5 \%)$ & $16(1.0 \%)$ & $36(7.2 \%)$ & \\
\hline \multicolumn{5}{|l|}{ Mother's employment } \\
\hline Full time & $968(46.9 \%)$ & $701(44.9 \%)$ & $260(51.9 \%)$ & \multirow[t]{3}{*}{0.570} \\
\hline Part time & $378(18.3 \%)$ & $298(19.1 \%)$ & $83(16.5 \%)$ & \\
\hline Unemployed & $718(34.8 \%)$ & $564(36.1 \%)$ & $159(31.7 \%)$ & \\
\hline Continuous Variables & $\begin{array}{c}\text { Overall } \\
\text { Mean }(S D)\end{array}$ & $\begin{array}{l}\text { Not Depressed } \\
\text { Mean }(S D)\end{array}$ & $\begin{array}{l}\text { Depressed } \\
\text { Mean }(S D)\end{array}$ & $p$ \\
\hline Mother's age & $29.1(7.3)$ & $29.0(5.9)$ & $29.4(10.0)$ & 0.710 \\
\hline Child's age & $2.2(0.4)$ & $2.2(0.4)$ & $2.2(0.5)$ & 0.823 \\
\hline Number of doctor's visits & $32.7(14.6)$ & $27.8(10.1)$ & $44.6(21.4)$ & 0.423 \\
\hline Number of well-child visits & $20.9(11.0)$ & $23.2(10.2)$ & $15.0(12.6)$ & 0.647 \\
\hline
\end{tabular}


Table 2

Individual Behaviors Stratified by Presence of Depressive Symptoms

\begin{tabular}{|c|c|c|c|c|}
\hline Variable & $\begin{array}{c}\text { Overall } \\
\mathrm{N}=2063(\%)\end{array}$ & $\begin{array}{l}\text { Not Depressed } \\
\mathrm{N}=1562(\%)\end{array}$ & $\begin{array}{l}\text { Depressed } \\
\mathrm{N}=501(\%)\end{array}$ & $\begin{array}{c}\text { OR } \\
(95 \% \mathrm{CI})\end{array}$ \\
\hline \multicolumn{5}{|l|}{ Routines } \\
\hline Family eats dinner together & $1142(68.3 \%)$ & $886(67.9 \%)$ & $256(69.4 \%)$ & $0.94(0.73-1.20)$ \\
\hline Family eats breakfast together & $510(66.5 \%)$ & $385(65.4 \%)$ & $125(70.2 \%)$ & $0.80(0.56-1.15)$ \\
\hline Bed time same each day & $1481(71.8 \%)$ & $1158(74.1 \%)$ & $323(64.5 \%)$ & $1.58(1.27-1.96)^{* * *}$ \\
\hline Nap time same each day & $1324(65.9 \%)$ & $1047(68.6 \%)$ & $277(57.4 \%)$ & $1.63(1.31-2.01)^{* * *}$ \\
\hline Meal time same each day & $1532(74.3 \%)$ & $1198(76.8 \%)$ & $334(66.7 \%)$ & $1.65(1.32-2.06)^{* * *}$ \\
\hline \multicolumn{5}{|l|}{ Enrichment } \\
\hline Read stories to child & $938(61.8 \%)$ & $746(63.3 \%)$ & $192(56.3 \%)$ & $1.34(1.05-1.71)^{*}$ \\
\hline Music/sings with child & $1542(81.6 \%)$ & $1182(81.8 \%)$ & $360(80.9 \%)$ & $1.06(0.81-1.39)$ \\
\hline Takes child on outings & $749(44.5 \%)$ & $592(45.4 \%)$ & $157(41.4 \%)$ & $1.17(0.93-1.48)$ \\
\hline \multicolumn{5}{|l|}{ Punitive Behaviors } \\
\hline Often raises voice at child & $199(20.2 \%)$ & $117(16.8 \%)$ & $82(28.5 \%)$ & $0.51(0.37-0.70)^{* * *}$ \\
\hline Often spanks child & $35(10.1 \%)$ & $18(7.8 \%)$ & $17(14.5 \%)$ & $0.50(0.25-1.00)^{*}$ \\
\hline \multicolumn{5}{|l|}{ Positive Disciplinary Strategies } \\
\hline Often takes child toys/treats & $205(35.3 \%)$ & $146(33.8 \%)$ & $59(39.9 \%)$ & $0.77(0.52-1.13)$ \\
\hline Often gives child a time out & $266(42.7 \%)$ & $202(43.3 \%)$ & $64(41.0 \%)$ & $1.10(0.76-1.58)$ \\
\hline Often explains behaviors is wrong & $616(71.7 \%)$ & $471(73.5 \%)$ & $145(66.5 \%)$ & $1.39(1.00-1.94)^{*}$ \\
\hline \multicolumn{5}{|l|}{ Childproofing } \\
\hline Puts up baby gates & $1427(70.4 \%)$ & $1072(69.8 \%)$ & $355(72.3 \%)$ & $0.91(0.76-1.09)$ \\
\hline Lock/latches cabinets & $1571(78.5 \%)$ & $1203(79.6 \%)$ & $368(75.3 \%)$ & $1.20(1.01-1.43)^{*}$ \\
\hline Pad sharp edges & $1036(52.5 \%)$ & $784(52.8 \%)$ & $252(51.5 \%)$ & $1.03(0.89-1.21)$ \\
\hline Put stoppers in outlets & $1886(92.3 \%)$ & $1433(92.8 \%)$ & $453(90.6 \%)$ & $1.23(0.96-1.59)$ \\
\hline Lower hot water settings & $1045(53.4 \%)$ & $802(53.8 \%)$ & $243(51.9 \%)$ & $1.06(0.90-1.24)$ \\
\hline Have syrup of Ipecac at home & $820(39.9 \%)$ & $637(40.9 \%)$ & $183(36.7 \%)$ & $1.14(0.97-1.34)$ \\
\hline \multicolumn{5}{|l|}{ Coping } \\
\hline Cope well with parenting demands & $1308(64.2 \%)$ & $1094(70.2 \%)$ & $214(44.8 \%)$ & $2.91(2.35-3.59) * * *$ \\
\hline \multicolumn{5}{|l|}{ Social Support Present } \\
\hline Has emotional support & $367(17.8 \%)$ & $218(13.9 \%)$ & $149(29.9 \%)$ & $0.38(0.30-0.48)^{* * *}$ \\
\hline Has someone to watch child & $244(11.8 \%)$ & $139(8.9 \%)$ & $105(21.0 \%)$ & $0.37(0.28-0.48)^{* * *}$ \\
\hline
\end{tabular}


Table 3

Multivariable Regression Models Examining Relationship between Parental Depression and Parenting Behavior

\begin{tabular}{ll}
\hline Parenting Behaviors & OR (95\% CI) \\
\hline Routines & $0.68(0.54-.082)^{*}$ \\
Enrichment & ns \\
Punitive disciplinary behaviors & $1.51(1.15-1.92)^{* *}$ \\
Positive disciplinary behaviors & $\mathrm{ns}$ \\
Childproofing & $\mathrm{ns}$ \\
\hline
\end{tabular}

Note: Controlled for the following variables in each analysis: Family-centered care, Coping, Social support, Ethnicity

$* p<.05 ; * * p<.01$ 
Table 4

Logistic Regression Models

\begin{tabular}{llll}
\hline Outcome & Predictor & OR $(95 \%$ CI $)$ & $p$-value \\
\hline Routines & FCC & $1.12(1.03-1.23)$ & $0.011^{* *}$ \\
& Depressed & $0.68(0.54-0.82)$ & $0.018^{* *}$ \\
& Coping & $1.02(0.78-1.19)$ & 0.589 \\
& Social Support & $0.87(0.78-0.98)$ & 0.096 \\
Enrichment & Ethnicity & $0.75(0.49-1.29)$ & 0.365 \\
& FCC & $1.02(0.77-1.34)$ & 0.645 \\
Punitive Disciplinary & $0.95(0.77-1.12)$ & 0.487 \\
Behaviors & Copressed & $1.07(0.85-1.37)$ & 0.418 \\
& Social Support & $0.96(0.72-1.28)$ & 0.604 \\
& Ethnicity & $0.95(0.58-1.82)$ & 0.486 \\
& Depressed & $0.91(0.74-1.19)$ & 0.212 \\
Positive Disciplinary & $1.51(1.15-1.92)$ & $0.007 * *$ \\
Behaviors & Coping & $0.23(0.08-0.40)$ & $<0.001^{* *}$ \\
& Social Support & $0.17(0.03-0.39)$ & $<0.001^{* *}$ \\
& Ethnicity & $1.08(0.83-1.31)$ & 0.564 \\
& FCC & $1.03(0.84-1.20)$ & 0.845 \\
& Depressed & $0.88(0.74-1.02)$ & 0.141 \\
& Coping & $1.54(1.30-1.70)$ & $<0.001^{* *}$ \\
Child Proofing & Social Support & $1.37(1.14-1.68)$ & $<0.001^{* *}$ \\
& Ethnicity & $1.01(0.79-1.28)$ & 0.678 \\
& FCC & $1.08(0.87-1.19)$ & 0.404 \\
& Depressed & $0.91(0.79-1.03)$ & 0.227 \\
& Coping & $1.04(0.86-1.18)$ & 0.482 \\
& Social Support & $1.01(0.88-1.16)$ & 0.834 \\
& Ethnicity & $0.99(0.87-1.14)$ & 0.892 \\
\hline
\end{tabular}

